\title{
Reporting with and without role shift: sign language strategies of complementation
}

\author{
Josep Quer
}

\begin{abstract}
Role shift structures, characterized by a set of non-manual markers and indexical displacement, are the most genuine way for sign languages to convey linguistic reports. Contrary to what is often assumed, the analysis of Catalan Sign Language (LSC) data allows us to conclude that in role shift, we must distinguish at least direct quotes from indirect reports, on the basis of interpretive and syntactic contrasts. In addition, it is shown that role shift has a broader use in encoding attitude ascriptions. After discussing the possible syntactic analysis of the various surface positions of LSC clausal complements in general, role shift complements are argued to basically follow the same general patterns. In this sense, they must be seen as a modality-specific strategy of complementation, despite their apparent peculiarities.
\end{abstract}

\section{Introduction ${ }^{1}$}

Sign languages have been repeatedly described as displaying a genuine means to convey reports: role shift. This strategy superficially resembles enacting the individual whose utterances or thoughts are being reproduced or represented. ${ }^{2}$ However, the detailed analysis of role shift structures yields a much more complex picture. From a formal point of view, role shift is flagged through a rich combination of non-manual markers, and from an interpretive point of view, it is characterized by a shift of indexical reference to the reported context. These characteristics will be reviewed in Section 2. At face value, role shift fragments look like the equivalent of direct quotation in the visual-gestural modality; yet, although it can certainly serve this function, it will be argued in Section 3 that role shift marking appears with both direct quotes and indirect reports and, moreover, that it actually covers a broader empirical domain than just reports, because it extends into the 
area of attitude ascriptions more generally. Finally, in Section 4, a characterization of the basic syntactic distribution of role shift clauses is offered by placing them in the broader discussion of the syntax of clausal complements.

The empirical evidence supporting the characterization and analysis of the phenomenon of role shift will be drawn mostly from Catalan Sign Language (LSC), but is supported by some sporadic findings reported for other sign languages as well.

\section{Defining features of role shift}

The phenomenon identified in sign languages as role shift (also labeled role taking, role switching, reference shift, or in some cases constructed dialogue and constructed action, cf. Metzger 1995) is usually interpreted as a direct discourse report or quotation in the visual-gestural modality. It is the characteristic strategy these languages employ in order to convey the utterances or thoughts ascribed to a discourse agent, and sometimes to reproduce or rather recreate the dialogue between two or more subjects in a displaced context. It is characteristic of narrative discourse, but it is also found in other kinds of texts. Descriptions and analyses of the phenomenon in several sign languages have been offered by Padden (1986), Engberg-Pedersen (1995), Lee et al. (1997), Poulin (1994), Poulin \& Miller (1995), Lillo-Martin (1995, 2012), Zucchi (2004), Quer (2005, 2011, 2013a), Quer \& Frigola (2006), Herrmann \& Steinbach (2007, 2009, 2010), Schlenker (2010), Hübl \& Steinbach (2012), and Hübl (2013), among others.

Descriptively, role shift is characterized by two sets of properties: on the formal side, by a set of non-manual markers that flag the utterance(s) as reported from the perspective of the quoted illocutionary agent; on the interpretive side, by the referential displacement that $1^{\text {st }}$ and $2^{\text {nd }}$ person markings and other indexicals, when present, undergo in the scope of role shift. In the following, both types of properties are briefly described.

\subsection{Non-manual markers}

The prototypical articulations that can mark role shift overtly include the following non-manual markers:

- Temporary interruption of eye contact with the actual interlocutor and change of direction in eye gaze towards the reported interlocutor (Figure 1). ${ }^{3}$

- Slight shift of the upper body in the direction of the locus associated with the author of the reported utterance (Figure 2). 
- Change in head position (Figure 3).

- Facial expression associated to the reported agent (Figure 4).
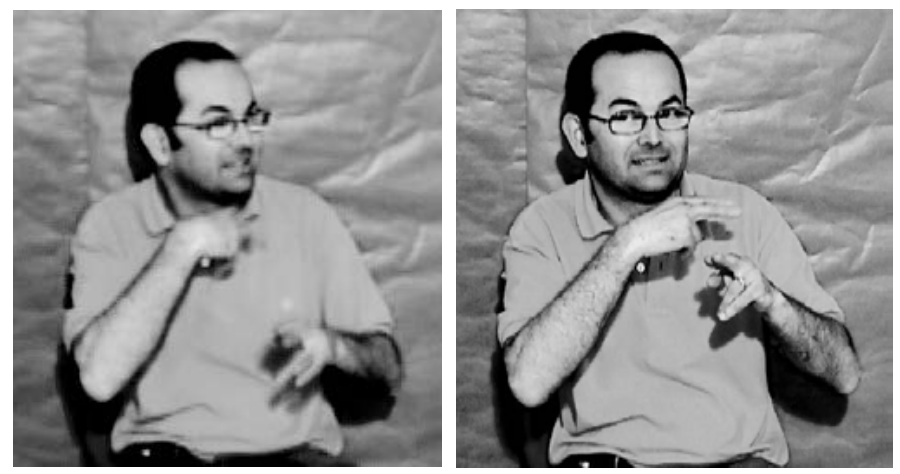

Figure 1. Eye gaze break.

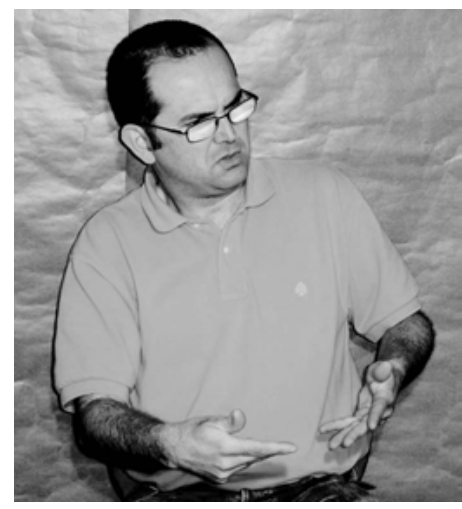

Figure 2. Body shift.

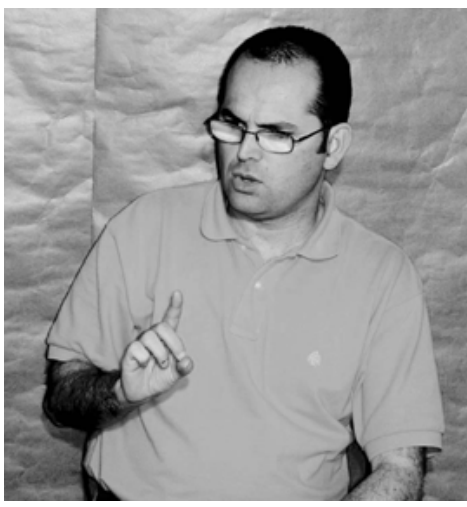

Figure 3. Head position change.

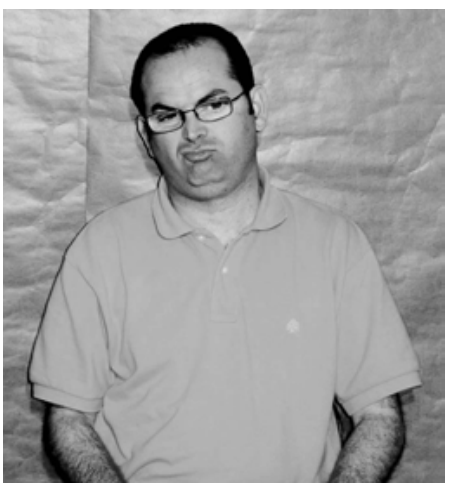

Figure 4. Facial expression. 
All these non-manual articulations can appear together in a role shift segment at the same time, but they are not all compulsory. On the basis of a small corpus study in German Sign Language (DGS), Herrmann \& Steinbach $(2009,2010)$ established that the only required articulation to mark role shift in that language is eye gaze break, as it seems sufficient to identify a discourse segment as role shift from a formal point of view. This finding is confirmed for LSC by signers' intuitions. It should be remarked that, even if marking by the whole set of non-manuals can make it very obvious, sometimes role shift is extremely subtle, especially when eye gaze is the only marker used to flag it.

\subsection{Interpretive characteristics}

In parallel to formal marking, role shift fragments involve referential displacement of indexical elements when they occur. First and second person pronouns and other grammatical elements agreeing with them (verbal person agreement, possessives, etc.) are not anchored to the main context of utterance, but to the reported context; in other words, $1^{\text {st }}$ and $2^{\text {nd }}$ person features do not refer in principle to the signer and the addressee of the main context but to those of the displaced one. Next to person indexicals, temporal and locative indexicals in the scope of role shift must shift in their reference and consequently, they get interpreted with respect to the derived context. An almost minimal pair of a report with and without role shift can be found in (1) and (2), respectively. ${ }^{4}$ Example (1) is a rather standard case of reported speech where pronouns and indexical reference are shifted to the derived context, and consequently IX-1 is interpreted as the referent of ANNA and not as the actual utterer of the sentence. The counterpart of (1) without role shift in (2) features a (topic-marked) $3^{\text {rd }}$ person pronoun co-referent with the main clause subject. The contrast in formal marking of those two pronouns can be observed in Figures 5 and 6.

RS-i

(1)

ANNA $_{i} 3$-SAY-2 IX- $1_{i}$ FED-UP LOSE +++

'Anna ${ }_{i}$ told you that she ${ }_{i}$ was fed up with losing so often.'

(2) ANNA $_{\mathrm{i}} 3$-SAY-1 $\frac{\mathrm{t}}{\mathrm{IX}-3}{ }_{\mathrm{i}}$ FED-UP LOSE +++

'Anna ${ }_{i}$ told me that she ${ }_{i}$ was fed up with losing so often.' 


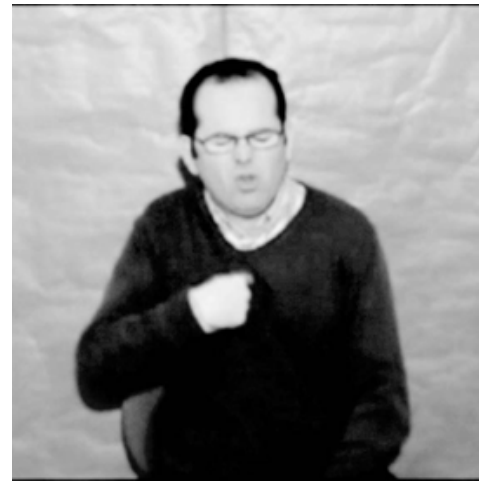

Figure 5. IX-1 $1_{\mathrm{i}}$ in (1).

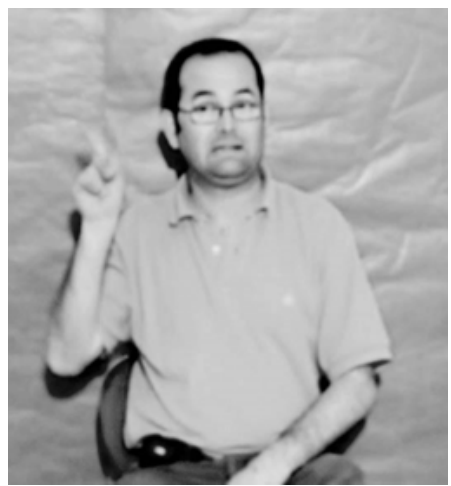

Figure 6. IX-3 in (2), with topic marking.

Given this description of the phenomenon, one could simply conclude that role shift is equivalent to direct quotation in the visual-gestural modality. However, LSC has a number of explicit markers of direct quotation such as the ones glossed as AUTHOR, DECLARE, VOICE, and SAY1-SENTENCE, ${ }^{5}$ illustrated in Figures 7 to 10.

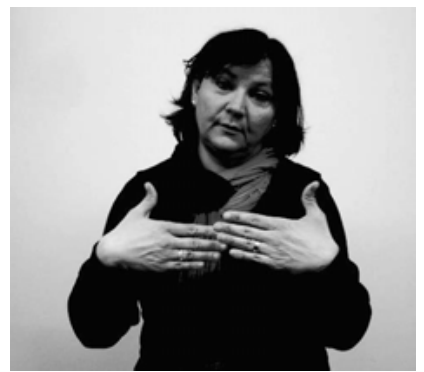

Figure 7. AUTHOR.

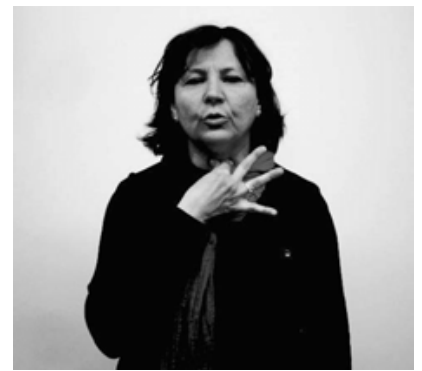

Figure 9. VOICE.

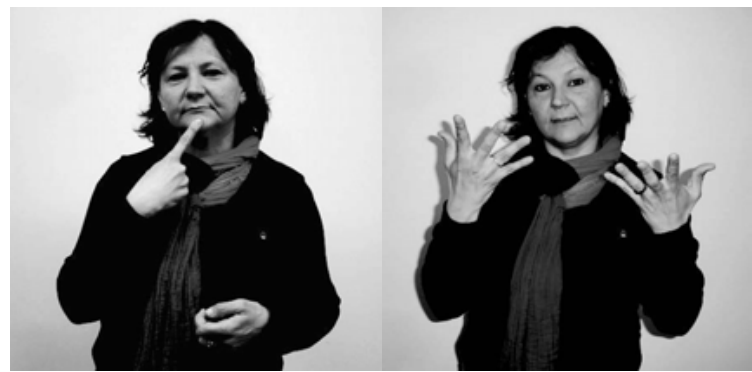

Figure 8. DECLARE.
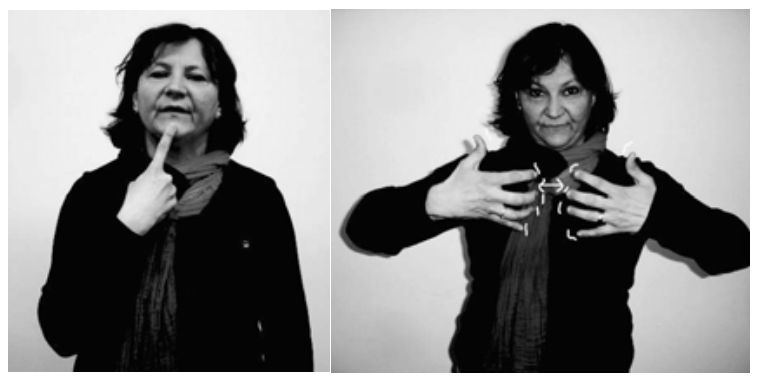

Figure 10. SAY1-SENTENCE. 
If one such marker introduces the role shift, it is unambiguosly interpreted as a direct quote, as in (3):

(3) ANNA $_{i}$ EXPLAIN SAY1-SENTENCE

RS-i

MAN! IX-1 BROTHER MAN 3-IGNORE-1

"Anna told me: "Man, my brother ignores me!"”

Such examples thus display a distinctive feature of direct quote, setting them apart from other lexical introducers such as SAY, THINK, REPLY (cf. Figures 11-13, for their uses as role shift introducers), which in their citation form are neutral with respect to the direct or indirect status of the report they flag.

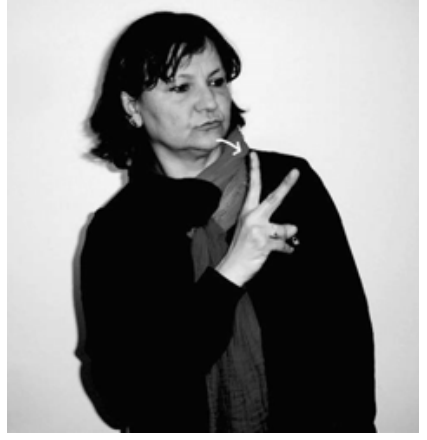

Figure 11. SAY.

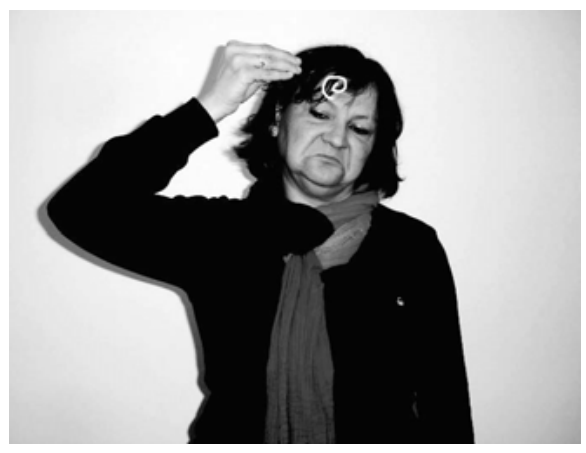

Figure 12. THINK.

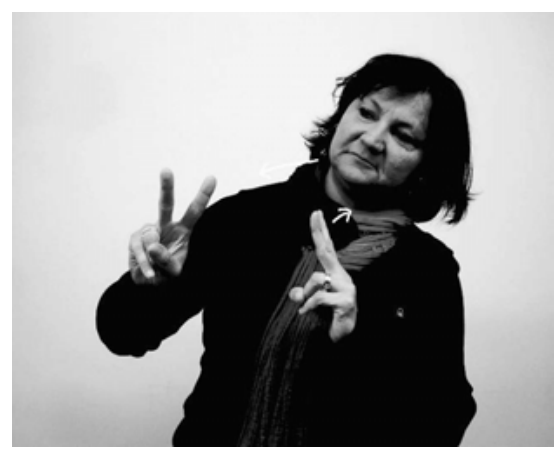

Figure 13. REPLY.

In spontaneous data and especially in connected discourse, we often find instances of reported discourse that are not explicitly introduced, or are introduced simply by indicating the agent of the reported utterance, as in example (4). 
$\frac{\mathrm{RS}-\mathrm{i}}{\mathrm{y} / \mathrm{n}}$
(4) LION
"The lion said: "Do you want to help me?!",

Furthermore, the structures that role shift marks are not only used to report utterances, but also the thoughts of an individual, as in (5). (The fact that the role shift marker extends over the predicate THINK will be subject to further discussion in Section 4.)

(5) $\frac{\mathrm{t}}{\text { IX-a MADRID JOAN }} \frac{\text { RS-i }}{\mathrm{T}}$

'When Joan was in Madrid, he thought about moving to Barcelona.'

In this sense, role shift not only serves the function of reproducing actual discourse, but also that of representing (re)constructed discourse or thoughts. This is not an uncommon feature of reported discourse at all, as we can see in (6) for English.

(6) And then Barack thought: "What am I going to say next?"

As argued in Quer (2013a), role shift can be shown to display some important properties that have been overlooked in most of the existing accounts of the phenomenon: it can appear in the scope of negation, quantified subjects, and modals. As I will detail next, I take these facts as non-prototypical for report or quotation, and I argue that they rather align role shift with attitude ascription marking.

In contrast to direct quotes under negation, a role shift fragment in the scope of a negative does not necessarily yield a corrective/contrastive reading of the embedded proposition that we find in cases like the English example in (7).

(7) David didn’t say “Leave me!" (but "Love me!").

Differently from this type of interpretations, LSC features examples like (8)-(11), where role shift is in the scope of a negative, but simply yields the negative attribution of a proposition to an individual or to a set of individuals. ${ }^{6}$ It is in this sense that the role shift structure turns out to be able to mark an attitude ascription more broadly, and not just reports of utterances or thoughts. 
RS-i

(8) JOAN ${ }_{i}$ SAY NEVER IX-1 $1_{i}$ ELECTIONS PARTICIPATE

'Joan never said that he wanted to run for the elections.'

hs

RS-i

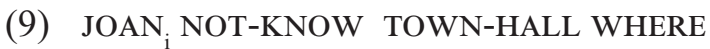

'Joan doesn't know where the town hall is.'

RS-i hs

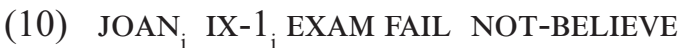

'Joan doesn't believe he has failed the exam.'

(11) IX-arc WARN-arc [CLASS CANCEL] $\overline{\text { NEG }^{7}}$

'No one warned them that the class was cancelled.'

In Figures 14-16, the relevant signs outside and within the role shift in sentence (11) can be observed: the plural pronoun IX-arc (Figure 14) precedes the role shift, the verb WARN-arc (Figure 15) is the first sign within the role shift, and the negative sign NEG2 follows the role shift.

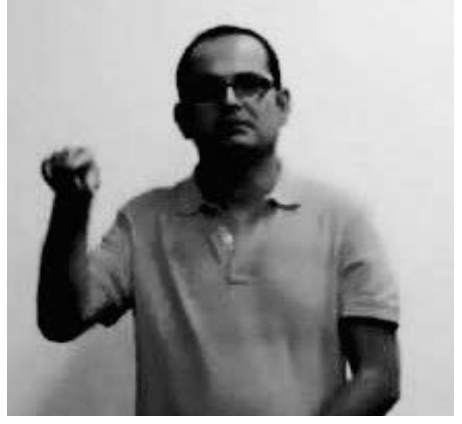

Figure 14. IX-arc.

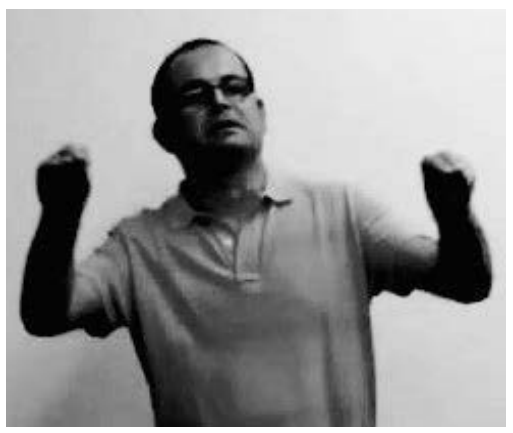

Figure 15. WARN-arc.

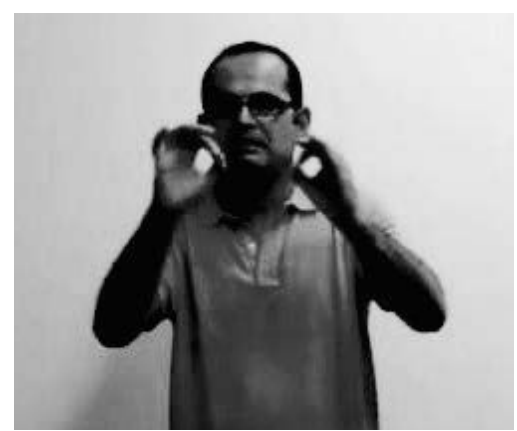

Figure 16. NEG2. 
In a similar fashion, role shift can also appear in the scope of a modal like CAN, as in (12), and in the scope of a quantified subject as well, as in (13) and (14).

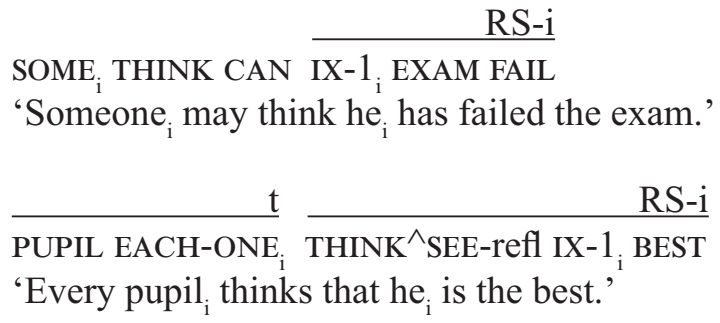

$\mathrm{RS}-\mathrm{i}$

SOME $_{\mathrm{i}}$ THINK CAN IX-1 ${ }_{\mathrm{i}}$ EXAM FAIL

'Someone ${ }_{i}$ may think he ${ }_{i}$ has failed the exam.'

$$
\text { NO-ONE }{ }_{\mathrm{i}} \text { SAY IX- } 1_{\mathrm{i}} \text { AGR- } 1^{8} \text { SCARED DARKNESS }
$$

'No one ${ }_{i}$ says he $_{i}$ himself is scared of darkness.'

These examples of role shift under negation, a modal, or a quantified subject do not yield a corrective/contrastive reading comparable to the one in (7) for English, but rather the unmarked one, where the signer attributes a propositional attitude to an individual or set of individuals (also negatively, as in (8)-(11) and (14)). Notice as well that the set of predicates that overtly introduce role shift is not restricted to verbs of saying and THINK, but it includes other typical propositional attitude predicates such as BELIEVE or KNOW, for instance.

The ability for role shift to naturally interact with negation, modals, and quantified attitude holders is a characteristic that arguably takes the phenomenon of role shift to the broader domain of attitude ascription marking. This does not mean that role shift must always mark an attitude ascription, as we saw in (2) that attitude ascriptions can also be expressed without role shift marking. It remains to be explored if there is a proper subset of attitude ascriptions that role shift can mark, and if so, what the shared property of that set is. In any event, on the basis of LSC data, it can be concluded that role shift is a cover term for a phenomenon that takes us beyond the limits of pure reports and serves the general function of encoding propositional attitudes more generally, by signaling an individual's perspective overtly. 


\section{Different types of reports under role shift}

The impression that role shift reports reduce to a single type of structure, namely direct quotes, cannot be maintained after considering the data just discussed in section 2.2. What is more, two apparently independent properties in LSC provide further support for that conclusion: the interpretation of indexicals and syntactic preposing of the reported clause. We will examine these two properties in turn.

\subsection{Shifted vs. unshifted indexicals}

Empirical evidence in LSC has been shown to contradict the generalization that Anand \& Nevins (2004) established, the Shift Together Constraint, according to which all indexicals appearing in the scope of a propositional attitude must shift, that is, we cannot find a situation where some indexicals in the scope of such an operator are interpreted in the derived context, while other indexicals are interpreted in the main context of utterance. However, Quer $(2005,2011)$ discusses cases like the following in LSC.

${\text { IX- } \mathrm{a}_{\mathrm{m}} \text { MADRID MOMENT JOAN }}_{\mathrm{i}} \frac{\mathrm{t}}{\text { THINK }^{-i}}$
'When he was in Madrid, Joan thought he would finish his study here
(in Barcelona).'

This sentence, uttered in Barcelona, reports on Joan's thoughts while he was in Madrid. In the report marked with role shift, we find two indexicals: the personal pronoun IX-1 and the locative indexical HERE. The $1^{\text {st }}$ person pronoun is interpreted, as expected, as referring to the utterer of the derived context that is being reported. Unexpectedly, though, the locative HERE does not receive the shifted interpretation ('in Madrid'), but the main context one ('in Barcelona'). ${ }^{9}$ This does not mean that such an indexical can never be interpreted in the shifted context: as (16) shows, there is no problem to get that reading if the location parameter of the embedded context is specified overtly. In that case, we only obtain the shifted interpretation.

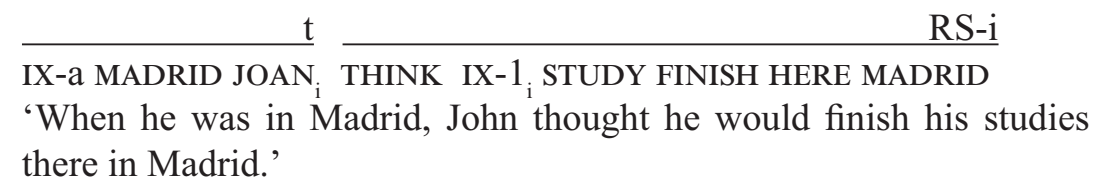


Such behavior of indexicals in role shift is not limited to locatives: a comparable pattern is found in temporal deixis with elements such as YEAR-THIS ('this year') or NOW in the same environment, as illustrated in (17) and (18), respectively.

$\mathrm{t}$

PERIOD LAST-YEAR JOAN IX-3 $_{\mathrm{i}}$ THINK STUDY FINISH YEAR-THIS 'Last year, Joan thought he would finish his studies \{this year $>$ thenthat year\}.'

$\mathrm{t}$

LAST-YEAR JOAN THINK IX-1 $_{i}$ STUDY FINISH NOW

'Last year, Joan thought he would finish his studies \{now $>$ then $\}$.'

For these indexicals, the interpretation with the temporal parameter of the main context is clearly the one that is strongly preferred over the shifted interpretation, although the latter is not excluded. The possibility for indexicals not to shift in embedded contexts has also been documented in German Sign Language (DGS; cf. Herrmann \& Steinbach 2012). ${ }^{10}$

Hübl \& Steinbach (2012), in their discussion of a comparable set of data in DGS, argue that the non-shifted interpretations of indexical elements might be due to their form, as in DGS, the signs for HERE, TODAY, and NOW are realized as an index pointing to the ground. Their conjecture is that through these indexical points, the actual context re-enters the role shift segment, so to say. In any case, even if at first sight, an explanation based on the pointing nature of some non-shifted indexicals seems intuitively appealing, personal indexicals pose a problem, as the first person pronoun does point to the chest of the actual signer in the role shift segment, and still it is unable to get interpreted with respect to the utterer-parameter of the main context. ${ }^{11}$ This means that if deixis to the main context were at play with HERE and TODAY in LSC and DGS, it would be of a different nature from the one present in IX-1, and this needs further motivation. ${ }^{12}$

After having gone through the main properties of indexical interpretation in role shift, we are now in a position to establish an important distinction among role shift types. Examples like (15) or (17) illustrate that a locative or temporal indexical can be interpreted with respect to the main context, but this possibility remains excluded when role shift is introduced as direct quote by one of the markers mentioned in Section 2.2 above. Take for instance (19), which forms a minimal pair with (17), the only difference being that role shift is introduced overtly by DECLARE, a marker of direct quotes. ${ }^{13}$ 


\section{(19) PERIOD YEAR-LAST IX-3 JOAN $_{i} \overline{\text { THINK DECLARE }}$ \\ $\mathrm{RS}-\mathrm{i}$ \\ RS-i}

IX-1 $1_{i}$ STUDY FINISH YEAR-THIS

'Last year Joan thought: "I'll finish my study this year.",

Given the picture drawn so far, the striking fact is that in this case, the temporal indexical YEAR-THIS cannot possibly be interpreted in the main context of utterance but is obligatorily interpreted in the reported context, despite its occupying the same position in the clause and being marked by the same set of non-manual features as in (17). This contrast must be taken as clear evidence that role shift structures cannot be identified exclusively with direct quotation, contrary to some superficial characterizations of the phenomenon. Rather, we are forced to conclude that reports marked with role shift instantiate both direct and indirect speech: cases like (19) are unambiguously instances of direct speech, while examples like (17) are ambiguous between direct and indirect speech. ${ }^{14}$ In the next subsection, a further contrast of syntactic nature between the two types of reports will be described.

\subsection{Fronting of the report}

An additional property that distinguishes direct quotes from indirect reports with role shift is of a syntactic nature. Direct quotes in LSC can be preposed (topicalized) vis-à-vis the introducing main clause, as shown in (20), where SENTENCE SAME ${ }^{15}$ is the marker of direct discourse. In contrast, ungrammaticality results if we try to do the same with a role shift segment which is meant to be interpreted as indirect discourse, as in (21).

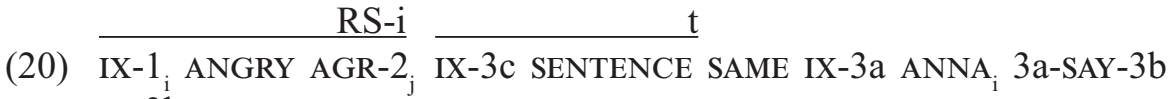
IX-3b PEDRO

“'I'm angry at you" said Anna to Pedro.'

RS-i

(21) *IX-1 ANGRY AGR-2 YeSTERDAY IX-3a ANNA A $_{\mathrm{i}}$ a-SAY-3b IX-3b PEDRO 'Anna said to Pedro that she was angry at him.'

In addition, a reportative complement clause that is not marked with role shift can also be preposed to the main verb, as (22) illustrates. 


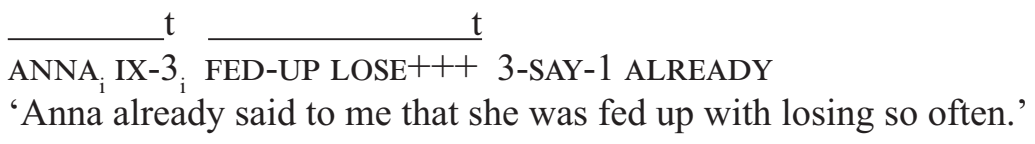

'Anna already said to me that she was fed up with losing so often.'

On the basis of this evidence, we must conclude that role shift structures in LSC do not form a uniform class and that they actually serve the expression of both direct and indirect reported discourse. The contrasting properties that we were able to identify so far were, on the one hand, the differing interpretation of locative and temporal indexicals in each type, and the possibility to prepose the reportative clause, on the other.

\section{Syntactic distribution of clausal complements and role shift argu- ment clauses}

An obvious question to ask at this point is whether clauses marked with role shift are syntactic complements of the introducing predicate, if they are introduced by one at all. ${ }^{16}$ There are two main reasons to think that that is indeed the case:

(i) Role shift marking spreads sometimes not only onto the reportative clause but also over the introducing predicate (see (5) or (19) above). If overt marking is triggered by a covert point of view operator in the CP domain of the embedded clause, ${ }^{17}$ as argued for in Quer $(2005,2011)$, it necessarily spreads over its c-command domain, just like other operator-triggered non-manual markers (cf. Neidle et al. 2000).

(ii) Negation, quantifiers, and modals can take scope over the reportative clause, as was illustrated above in (8)-(14).

Lillo-Martin (1995) provides empirical arguments for the embedded status of the reported clause in ASL. Yet, Lee et al. (1997) treat examples of role shift in ASL as instances of reported direct speech or direct quotation realized as two juxtaposed clauses. Although such cases do seem to exist in LSC as well, we have seen that role shift structures also appear in constructions where reported direct speech cannot be at play. If we put direct quotes aside, which can be preposed, role shift complements canonically appear postverbally. But is this the canonical position for clausal complements in general? In this section, we will delve into the syntactic distribution of clausal complements in LSC more generally in order to determine to what extent role shift clauses are just a subset of clausal complements. 
Argument clauses in LSC tend to appear either at the left or right edge of sentences, as exemplified in (23a) and (23b), respectively, and thus they show the same tendency that was described for Italian Sign Language (LIS) in Geraci et al. (2008).
re
hs
a. CLASS CANCEL 3-WARN-1 $\overline{\text { NEG2 }}$
'No one warned me that the class was cancelled.'
hs
b. 3-WARN-1 NEG2 [IX-a CLASS CANCEL]
'No one warned me that that class was cancelled.'

These two options will be discussed in turn in the following two subsections.

\subsection{Left-edge clausal complements}

Interestingly, the sentence initial occurrence of the clausal complement is co-articulated with raised eyebrows, the non-manual markers associated with topics (23a), while the sentence final one does not seem to receive any special kind of non-manual marking (23b).

LSC has SOV as its basic word order. Previous research on the syntax of the language has shown that functional heads in general (such as Negation or Aspect) are final, and that SpecCP, the landing site for wh-phrases, is to the right (Quer 2002/2007; Alba 2010). The basic spine in LSC for a wh-subject interrogative clause is represented in a simplified fashion in Figure 17.

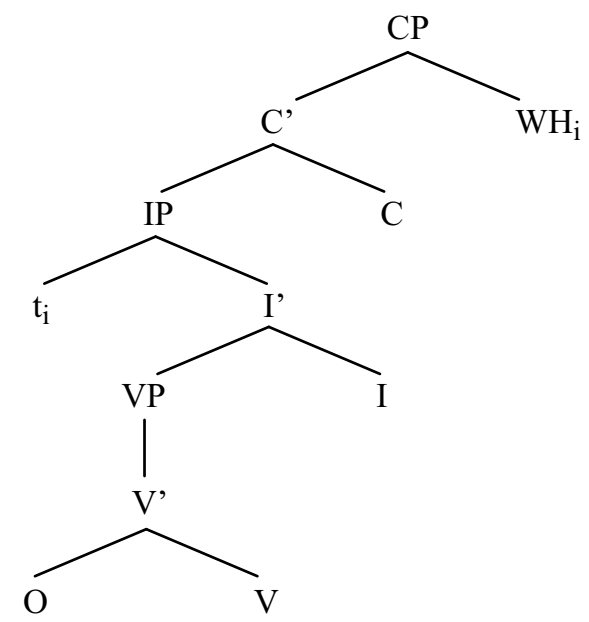

Figure 17. Basic clausal spine in LSC for a wh-subject interrogative. 
The left-edge occurrence of the complement clause in (23a) can be interpreted as sitting in the Spec position of a Topic Phrase (TopP), as depicted in Figure $18 .{ }^{18}$ In that peripheral position, it is overtly marked with raised eyebrows and it is co-indexed with the empty object position of the main verb. Being an unrestricted argument-drop language, LSC does not require a resumptive element in that position (Quer \& Rosselló 2013). The doubling pronoun linked to the sentential object in SpecTopP in (24) is also marked with the non-manual associated with topic, so we have to assume it is either a second topic (topics can recur unproblematically in LSC) or a determinerlike element accompanying the $\mathrm{CP}$.

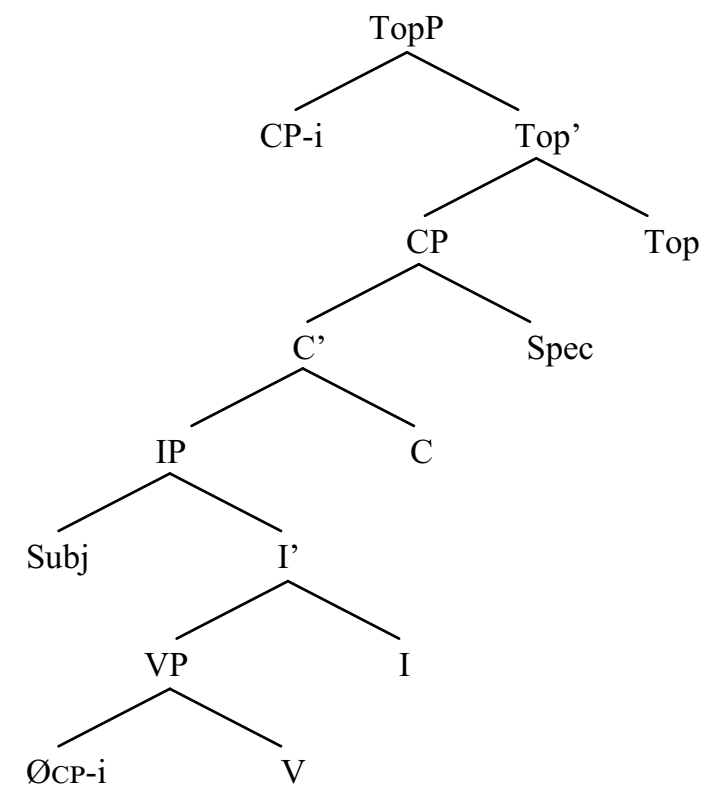

Figure 18. Structure for a clausal CP-object occurring at the left edge in LSC (TopP version).

$\frac{\text { re }}{{\text { [CLASS CANCEL }]_{i} \mathrm{IX}_{\mathrm{i}}}_{\mathrm{LIKE}^{\wedge} \mathrm{NOT}}^{\mathrm{hs}}}$
'I didn't like it that the class was cancelled.'

As a matter of fact, it is not clear at all that what we loosely call "topic" for the sake of simplicity - because it is marked with brow raise - is actually a topic in the information-structural sense. In fact, the ordering sentential complement-main clause is very often used in cases where the embedded clause is part of the asserted information of the utterance, and thus not necessarily 
backgrounded as a link in the sense of Vallduví (1992). Putting aside further investigation into this matter for the time being, I tentatively suggest that left-edge sentential complements are marked with raised eyebrows not because they are topics, but rather because of the prosodic bounding of the complex sentence. From this point of view, TopP in Figure 18 may actually be a misnomer for a position that hosts material that is not prosodically integrated into the intonational phrase constituted by the main clause, but forms a syntactic and interpretive unit with it (maybe with the very general interpretation of continuation dependency proposed by Dachkovsky \& Sandler (2009) for Israeli Sign Language). Still, the sentential argument must be hierarchically the highest constituent, as the rest of the manual material in the main clause appears linearly after it and right-peripheral elements like wh-phrases in SpecCP close the CP domain. Postulating a specialized projection TopP with a head on the right creates more problems for the analysis than it actually solves (for instance, there is no evidence that the head $\mathrm{Top}^{\circ}$ is ever realized by overt material in LSC, unless we take brow raise as its overt realization). For this reason, the syntactic structure in Figure 18 is tentatively abandoned for a new one where TopP is absent and the left-edge CP object is simply adjoined to the matrix CP, as depicted in Figure 19.

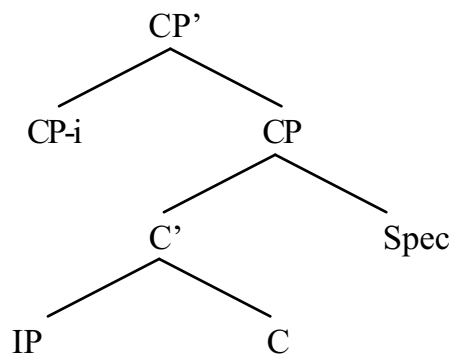

Figure 19. Partial structure for a clausal CP-object occurring at the left edge in LSC (adjunction to matrix $\mathrm{CP}$ version).

There is strong empirical evidence to believe that Wilbur \& Patschke's (1999) proposal, according to which brow raise in ASL is marking material in A'-specifiers of a [-wh] operator head, is similarly applicable to LSC in many structures featuring this non-manual marker. In ASL, though, SpecCP is argued to be on the left, unlike in LSC, where it branches to the right. Wilbur \& Patschke additionally assume adjunction to CP for topics, left dislocations, conditional antecedents, and when-clauses. In fact, (24) could be analyzed along those lines: it is plausible that the negative predicate LIKE $^{\wedge}$ NOT has moved up to $\mathrm{C}^{\circ}$, attracted by the focus operator feature F (cf. 
Wilbur \& Patschke 1999). However, in the LSC example (24), the left-edge clause brow raise would not be triggered by Spec-head agreement with the F-marked $\mathrm{C}^{\mathrm{o}}$, but simply by being adjoined as a second (left) specifier to $\mathrm{CP}$. Note that, given the analysis so far, the prediction is that we can have both the SpecCP to the right and the adjunction site to the left of $\mathrm{CP}$ overtly realized in the same structure. This prediction seems to be borne out in cases involving a left-edge sentential object and a wh-main clause interrogative on the right. This is illustrated in example (25), which thus lends support to the structural account of left-edge clauses proposed so far. ${ }^{19}$

$\frac{\text { re }}{\text { [CLASS CANCEL }]_{i} \text { IX-i }} \frac{\text { wh }}{\text { WARN WHO }}$
'Who warned that the class was cancelled?'

\subsection{Right-edge clausal complements}

Let us now turn to instances of right-edge argument clauses like (23b). As pointed out above, one distinctive feature of these occurrences of embedded sentential complements is that they are not marked non-manually with brow raise, as opposed to their left-edge counterparts. Since LSC is underlyingly $\mathrm{OV}$, the object clause appears on the "wrong" side of the verb, as has also been reported for LIS and the Germanic languages like German or Dutch (for discussion, see Quer 2013b). This order cannot be accounted for by arguing that the object clause is actually in its base position and that what has been moved is the verb to the left: given the right-headedness of functional projections in LSC, head-to-head movement of $\mathrm{V}$ to a higher inflectional head would still lead to an OV ordering.

The first task to carry out is to determine the distribution of the embedded $\mathrm{CP}$ with respect to other landmarks in the clausal spine that might provide us with clues about the actual position of the object clause in the hierarchy. One important piece of evidence is provided by example (26): on the one hand, it seems that the bracketed clause can be rather high in the structure, as the perfect marker ALREADY materializes a right $\mathrm{Asp}^{\circ}$ head in the inflectional domain; on the other hand, the interrogative yes/no-marking must be taken to indicate that the relevant $\mathrm{Q}$ operator responsible for the non-manual signal is sitting in $\mathrm{C}^{\mathrm{o}}$ to the right, and that the non-manual spreads over the operator's c-command domain, namely over the whole sentence. 
3-WARN-2 ALREADY [IX-a CLASS NOT-BE]

'Did they already warn you that there is no class?'

A sentence that could constitute an almost minimal pair with (26) is presented in (27), where the embedded clausal object appears at the left edge of the clause, marked with brow raise, as expected.

re $\frac{\mathrm{y} / \mathrm{n}}{2}$

[CLASS NOT-BE] WARN-3 ALREADY

'Did they already warn him that there is no class?'

A further relevant fact for the characterization of the empirical picture of clausal arguments in LSC is the one reproduced in (28), which features a non-sentence final object CP: the main clause is a wh-interrogative whose wh-element is a subject extracted from the embedded clause. There is no doubt about the scope of the wh-phrase, as the main predicate THINK cannot take an interrogative clause as complement. The embedded CP appears postverbally and in hierarchical terms, it must be placed below the matrix $\mathrm{CP}$ where the wh-phrase is sitting. Still, the most interesting property of this example is that it shows that postverbal sentential objects are not islands for extraction, unlike what has been found in LIS but similarly to what has been reported for Dutch and German.

$$
\begin{aligned}
& \frac{\text { re }}{\mathrm{IX}^{\wedge} 2-3 \text { DISCUSSION }} \frac{\text { wh }}{\text { IX-2 THINK [IX } 2-3 \text { BE-RIGHT] WHO }} \\
& \text { 'In the discussion between those two, who do you think is right?' }
\end{aligned}
$$

With all these pieces of evidence in front of us, it seems safe to conclude that left-edge and right-edge occurrences of clausal arguments in LSC have rather different properties, as had already been established for Dutch, German, and LIS, for instance. The main question posed in Quer (2013b) concerning these data was whether clausal complements in LSC must necessarily appear in such peripheral positions. Closer examination of the core relevant data in LSC reveals that, despite a general tendency to occupy such peripheral slots, clausal complements are not excluded from certain non-sentence final positions. At this point, the open issue is which exact positions those "medial" occurrences, as in example (28), can occupy.

In dealing with CP-extraposition in German, Haider (2010) discards accounts based on right-detachment of the $\mathrm{CP}$ at $\mathrm{PF}$ because that type of 
approach is not selective enough, it cannot discriminate among the clear syntactic conditions that allow or disallow extraposition, and it cannot account for the semantic effects that correlate with it. On the other hand, the syntactic rightward movement approach is faced with a whole array of empirical inadequacies, beyond the theoretical debate about the legitimacy of rightward movement itself. Among other problems, there are important asymmetries between uncontroversial cases of movement like scrambling or topicalization and extraposition, for instance.

In front of the limitations of these two kinds of approaches, Haider opts for a base-generation type of analysis, which takes extrapositions as detached elements that are generated at a distance from their antecedent or base positions. The extraposed constituent would be related to the antecedent through a construal relation. The tentative implementation that he proposes for the analysis is to have an optional, low shell that hosts the extraposed elements. Haider (2010: 233) argues that "languages may differ with respect to the availability of this shell". For instance, strict head-final languages like Japanese that do not have extraposed structures would lack this shell.

If we follow Haider's reasoning, the main question to ask is where such an extraposition shell should be projected in LSC. The CP complement in LSC can sometimes be really low, arguably in its base position, as we can see in (29a), but the real puzzle is where the postverbal CP is located in examples like (29b).

a. JOAN [IX-1 CAR SELL ALREADY] FORGET

b. JOAN FORGET [IX-1 CAR SELL ALREADY]

'Joan forgot that I already sold the car.'

Among the postverbal clausal objects that do not need to be sentence-final is the one illustrated in (11), repeated here as (30), where the main verb and its object CP appear to the left of the main clause negation. That material is marked by role shift, but it is still embedded within the core clause, as the non-topical object pronoun at the beginning of the sentence indicates.
$\mathrm{RS}$
IX-arc WARN-arc [CLASS CANCEL] NEG2
'No one warned them that the class was cancelled.'

For the LSC cases that display a sentential complement after the verb or some inflectional element like Aspect or Negation, but still with a wh-element following it (cf. (28) above), all other things being equal, we are forced to 
admit that there must be at least a locus for extraposed clauses in the IP domain. ${ }^{20}$ Such a position would need to be a specifier or an adjunction site right below the CP domain, as examples like (28) make us conclude. At this point, a more specific implementation of these ideas cannot be carried out, mostly due to the lack of a better understanding of other phenomena that we would need to have command of in order to compare the LSC extraposition cases to the extensively studied extraposition phenomena in languages like Dutch and German.

Returning now to role shift complements, we have observed above that they systematically tend to occur postverbally, one of the two non-base options available for regular CP complements not accompanied by role shift. Left-detachment of reportative complements is only available for direct quotes and it probably involves a more complex structure mediated by clausal anaphora through an index linked to the independent quote clause. Indirect quote complements with role shift, on the other hand, appear to be excluded from left-detached positions. ${ }^{21}$ Next to left- and right-detached positions, role shift marked complements seem to be able to appear in a lower IP position yet to be determined, as we saw in (30). What seems most relevant in the current discussion about the characterization of role shift complements is that they do fit the general patterns of syntactic distribution displayed by regular CP complements in LSC, with some specific restrictions related to the status of quotes and to the spreading of role shift non-manual markers.

\section{Conclusion}

This chapter has offered an overview of reportative clauses in LSC. After examining their formal marking and the peculiarities of indexical interpretation, we have been able to establish that role shift occurs with reports of two kinds: direct quotes and indirect reports. In addition, reports can also be realized without role shift marking, as in regular indirect discourse.

As a matter of fact, role shift does not only mark reports of actual or (re)constructed utterances or thoughts, but it also extends into the broader domain of attitude ascriptions, as its occurrence under negation, modals, and quantified subjects in the introductory clause has made clear.

Finally, a first attempt has been made in order to ascertain the syntactic status of role shift-marked CP complements with respect to the main clause. Apart from a few expected differences, reportative complements marked by role shift follow the same general pattern as other clausal complements, but with a clear preference to appear postverbally as an "extraposed" constituent. 
Pending further detailed investigation into the intricate details of the syntax of extraposition, what is important to remark in the context of the present discussion is that role shift reportative CPs turn out to behave just like any other regular clausal complement despite their surface idiosyncrasies.

\section{Notes}

1. This chapter offers an overview of a research project the results of which are reported in Quer $(2005,2011,2013 a)$ and Quer \& Frigola (2006) and expands on it by incorporating new results from Quer (2013a,b). I would like to thank the audiences at the Lichtenberg workshop Complex sentences and beyond (Göttingen 2011), the $13^{\text {th }}$ Texas Linguistics Society conference (Austin 2012), and the Göttingen Fall School Non-canonical forms of reported discourse in spoken and sign languages (2012) for their valuable comments and criticism. The current version has benefited a lot from detailed comments and questions by two anonymous reviewers, whom I thank warmly. Special thanks go to Annika Herrmann, Annika Hübl, and Markus Steinbach. All remaining errors are obviously my responsibility. This work would have been impossible without the collaboration of my Deaf colleagues Santiago Frigola and Delfina Aliaga. The research was partly supported by grants awarded by the Spanish Ministry of Science and Innovation to Josep Quer (FFI2009-10492 and FFI201236238), by the Govern de la Generalitat de Catalunya (2009SGR00763), and by SignGram COST Action IS1006.

2. With this definition, I intentionally leave out of the scope of this work the phenomenon known as constructed action, which systematically co-occurs with reportative role shift in narrative discourse. Within constructed action, the signer adopts the role of the referent in order to reproduce not his/her linguistic utterances, but his/her actions, postures, or gestures in a more or less imitative fashion. This aspect is less well understood, although it is found regularly in the descriptions of narrative techniques in sign languages (see Quinto-Pozos 2007; Cormier et al. 2013). The term role shift is often used in a descriptive way to talk about the two types of phenomena. They are not always easy to tease apart, but in this paper, I concentrate on its use for linguistic reports. For some relevant discussion, see Quer (2013a: 17-19).

3. This holds for the prototypical cases where eye gaze is directed towards the actual interlocutor and is diverted to another virtual interlocutor when entering role shift. As an anonymous reviewer points out, it might be the case that eye gaze is not directed to the interlocutor before the role shift fragment, or that there is no virtual interlocutor in the role shift. Still, the crucial property is that there is a clear change in eye gaze direction (excluding the actual interlocutor) in all cases. 
4. The usual glossing conventions in the sign language literature are followed here, according to which manual signs are represented by the capitalized word corresponding to the translation of the sign. The relevant abbreviations for the purposes of this paper are the following ones: \#-VERB-\# (verb agreeing with subject and object; the number before the verb refers to the grammatical person of the former and the one after the verb refers to the latter); IX-a (locative index pointing to locus $a$ ); IX-\# (pronominal index; the number corresponds to person specification); AGR-\# (free person agreement morpheme); +++ (reduplication of the sign). The scope of non-manual markings is represented with a line that spreads over the manual material with which it is coarticulated; the following abbreviations are used for non-manual markers: eg (eyegaze); hs (negative headshake); RS (role shift); t (topic marking); re (raised eyebrows); wh (wh marking). The referential indices $i, j$, etc. link the first person role in RS fragments to the intended author of the reported utterance, if it has been previously introduced. With 'RS', I indicate all combinations of non-manual markers that identify a fragment of the utterance as being under role shift.

5. Note that the signs SAY and SAY1 are different: the former is an agreeing verb with a V-handshape (Figure 11), while the latter is a plain verb with a 1-handshape (Figure 10).

6. The contrastive/corrective reading is not excluded in these LSC examples, but it is much less prominent and highly dependent on contextual information and the use of codas. The LSC sentences reported here receive a non-contrastive/ corrective reading, as stated in the text.

7. NEG2 is one variant of the set of negative markers in LSC; it is illustrated in Figure 16.

8. The sign AGR-\# here glosses a multi-purpose sign that derives from the lexical sign PERSON and is often used to mark agreement with one argument, to extend the valency of a predicate, or, as is the case here, to emphasize an argument.

9. The position where the indexical appears seems to play a role: if not in sentencefinal position, it is preferably anchored to the derived context. At this point, it is not clear why the position of the indexical should affect its interpretation, but a plausible explanation might lie in the information structure status of the relevant item, namely focal in sentence-final position vs. non-focal sentenceinitial or sentence-medial position. It remains to be understood, then, why and how focus influences indexical interpretation in such structures.

10. Schlenker (2010) and Lillo-Martin (personal communication) report that independent shift of indexicals has not been documented for ASL. Nevertheless, Schlenker notes that it is possible to unshift an indexical if role shift markers are not coarticulated with it. Such cases are different from the LSC ones discussed in the main text, where the indexicals are in the overt domain of role shift marking. Overt unshifting by "switching off" the role 
shift non-manuals has also been observed in LSC, but it arguably constitutes a different case from the ones exemplified in (15) and (17)-(18).

11. A $1^{\text {st }}$ person pronoun in role shift can be co-referential with the utterer of the main context, but because both referents are identified in the discourse model as one and the same, and not directly. Notice that the situation is different with $2^{\text {nd }}$ person pronouns in role shift, as they are normally not directed to the actual interlocutor, but to a reported one located off the axis between signerinterlocutor.

12. An anonymous reviewer points out that with IX-1 the difference lies in the fact that it is a pronoun, but that is exactly the point made in the text: why do (indexical) pronouns behave differently from (indexical) adverbials?

13. An anonymous reviewer mentions the possibility that direct quotes might be marked by a special non-manual as well. If that is the case, this has not been identified yet in LSC, but nothing excludes that such an additional marking exists.

14. This amounts to saying that examples like (1), for instance, are ambiguous between direct and indirect speech, and that on the indirect speech reading, it is equivalent to (2). This might go against the predominant intuition that role shift is linked to direct speech because of its iconic component, but the subtleties of the distinctions discussed here and in related work (e.g. the fact that indexicals do shift under role shift in certain cases, which is impossible in direct quotes) actually argue for such a position.

15. Note that SENTENCE does not form a constituent with SAME, but rather with the index referring to the quoted utterance. SAME establishes identity with it in the main predication.

16. Some other examples instantiate the possibility for role shift to occur independently, as in as (4) above or (i) from ASL. Here, no overt predicate introduces the report and only the attitude holder MOM is made explicit (LilloMartin 1995).

\section{RS-i}

(i) MOM $_{\mathrm{i}}$ IX-1 ${ }_{\mathrm{i}}$ BUSY

'Mom's like, I'm busy!'

These examples are peculiar as the role shift is not explicitly introduced. In Quer (2011), I claim that what has been called "non-quotative RS" is plain role shift lacking an explicit introducer, but it is licensed by a preceding one or simply by the discourse context. This is actually the default in extended narrative discourse, where illocutionary agents have been established and utterance/thought reports are regularly interspersed in the narration.

17. 'Covert' is taken to mean here 'not realized at the manual level'. Of course, the morpho-phonological marking it triggers is overt. One should also distinguish the syntactic configuration of c-command, which is relevant for non-manual spreading, from the semantic notion of scope, which has interpretive 
consequences. It is important to keep in mind that constituents that are higher in the structure than a relevant operator like negation can still be under its scope through the empty (argument) position to which they are linked. This would apply to the instances of topic argument clauses under the scope of negation discussed in this paper (see (23a), for instance).

18. I am using here the notion of 'topic' in a rather shallow sense. Different types of topics might be identified in LSC at the syntactic and interpretive level, as in ASL (cf. Neidle et al. 2000), but the current state of knowledge about the language does not allow us to establish them. However, we will see below that we might need to postulate a lower topic-like position at the IP-level.

19. Unlike what Wilbur \& Patschke (1999) propose for ASL (i.e. left SpecCP), we claim that SpecCP is on the right in LSC. Examples like (i) provide strong empirical support for this position, as the complex wh-phrase can appear in the same position as the simplex one WHO in (18). This makes untenable the possible claim that the wh-element is actually sitting in $\mathrm{C}^{\mathrm{o}}$, as has been proposed for ASL.
(i) [CLASS CANCEL $]_{\mathrm{i}}$ IX-i
WARN TEACHER WHICH
'Which teacher warned that the class was cancelled?'

20. In the spirit of Belletti (2004), but with higher positions involved that do not receive a topic interpretation.

21. One way to account for the contrast would be to rely in each case on the different position of the Point of View Operator that triggers the non-manual marking of role shift, as well as its semantic effects (Quer 2005, 2011): while in both cases, it heads the reportative $\mathrm{CP}$, only in indirect quotes must it incorporate into the matrix predicate. This incorporation is blocked if the $\mathrm{CP}$ stands in a hierarchically superior position, as is the case with left-detached clauses.

\section{References}

Alba, Celia. 2010. Les interrogatives-Qu en llengua de signes catalana (LSC). MA thesis, Universitat de Barcelona.

Anand, Pranav \& Andrew Nevins. 2004. Shifty operators in changing contexts. In Robert B. Young (ed.), Proceedings of SALT XIV, 20-37. Ithaca, NY: Cornell University.

Belletti, Adriana. 2004. Aspects of the low IP area. In Luigi Rizzi (ed.), The structure of $C P$ and IP, 16-51. Oxford: Oxford University Press. 
Cormier, Kearsy, Sandra Smith \& Martine Zwets. 2013. Framing constructed action in British Sign Language narratives. Journal of Pragmatics 55. 119-139.

Dachkovsky, Svetlana \& Wendy Sandler. 2009. Visual intonation in the prosody of a sign language. Language and Speech 52(2/3). 287-314.

Engberg-Pedersen, Elisabeth. 1995. Point of view expressed through shifters. In Karen Emmorey \& Judy S. Reilly (eds.), Language, gesture, and space, 133154. Hillsdale, NJ: Lawrence Erlbaum.

Geraci, Carlo, Carlo Cecchetto \& Sandro Zucchi. 2008. Sentential complementation in Italian Sign Language. In Michael Grosvald \& Dionne Soares (eds.), Proceedings of WECOL 2008, 46-58. Davis: UC Davis.

Haider, Hubert. 2010. The syntax of German. Cambridge: Cambridge University Press.

Herrmann, Annika \& Markus Steinbach. 2007. Wenn 'ich' nicht ich ist: Redewiedergabe in Gebärdensprachen. In Elke Brendel, Jörg Meibauer \& Markus Steinbach (eds.), Zitat und Bedeutung. Linguistische Berichte Sonderhefte 15, 153-179. Hamburg: Helmut Buske Verlag.

Herrmann, Annika \& Markus Steinbach. 2009. Visible context shifts: Quotation in sign languages. Talk presented at the $42^{\text {nd }}$ Annual Meeting of the Societas Linguistica Europaea (SLE), Universidade de Lisboa, September 2009.

Herrmann, Annika \& Markus Steinbach. 2010. Eine neue Perspektive auf Role Shift in Deutscher Gebärdensprache (DGS). Perspektivwechsel als nichtmanuelles Kongruenzphänomen. Das Zeichen 84. 112-119.

Herrmann, Annika \& Markus Steinbach. 2012. Quotation in sign language. A visible context shift. In Ingrid van Alphen \& Isabelle Buchstaller (eds.), Quotatives: Cross-linguistic and cross-disciplinary perspectives, 203-228. Amsterdam: John Benjamins.

Hübl, Annika. 2013. Role shift, indexicals, and beyond - new evidence from German Sign Language. In Leah C. Geer (ed.), Proceedings of the $13^{\text {th }}$ Texas Linguistics Society Meeting, 1-11. Austin: Texas Linguistics Forum.

Hübl, Annika \& Markus Steinbach. 2012. Quotation across modalities: Shifting contexts in sign and spoken languages. Talk presented at the workshop Quotation: Perspectives from Philosophy and Linguistics, Ruhr-University Bochum, September 2012.

Lee, Robert G., Carol Neidle, Dawn MacLaughlin, Benjamin Bahan \& Judy Kegl. 1997. Role shift in ASL: A syntactic look at direct speech. In Carol Neidle, Dawn MacLaughlin \& Robert G. Lee (eds.), Syntactic structure and discourse function: An examination of two constructions in American Sign Language, 24-45. Report \#4, ASLLRP, Boston University.

Lillo-Martin, Diane. 1995. The point of view predicate in American Sign Language. In Karen Emmorey \& Judy S. Reilly (eds.), Language, gesture, and space, 155-170. Hillsdale, NJ: Lawrence Erlbaum. 
Lillo-Martin, Diane. 2012. Utterance reports and constructed action in sign and spoken languages. In Roland Pfau, Markus Steinbach \& Bencie Woll (eds.), Sign languages. An international handbook, 365-387. Berlin: De Gruyter Mouton.

Metzger, Melanie. 1995. Constructed dialogue and constructed action in American Sign Language. In Ceil Lucas (ed.), Sociolinguistics in deaf communities, 255-271. Washington, DC: Gallaudet University Press.

Neidle, Carol, Judy Kegl, Dawn MacLaughlin, Ben Bahan \& Robert G. Lee. 2000. The syntax of American Sign Language. Functional categories and hierarchical structure. Cambridge, MA: MIT Press.

Padden, Carol. 1986. Verbs and role-shifting in American Sign Language. In Carol Padden (ed.), Proceedings of the Fourth National Symposium on Sign Language Research and Teaching, 44-57. Silver Spring, MD: National Association of the Deaf.

Poulin, Christine. 1994. Null arguments and referential shift in American Sign Language. MIT Working Papers in Linguistics 23. 267-281.

Poulin, Christine \& Christopher Miller. 1995. On narrative discourse and point of view in Quebec Sign Language. In Karen Emmorey \& Judy S. Reilly (eds.), Language, gesture, and space, 117-131. Hillsdale, NJ: Lawrence Erlbaum.

Quer, Josep. 2002/2007. Operadores negativos en Lengua de Signos Catalana. In Sandra B. Cvejanov (ed.), Lenguas de señas: Estudios de lingüística teórica y aplicada, 39-54. Neuquén: Editorial de la Universidad Nacional del Comahue, Argentina.

Quer, Josep. 2005. Context shift and indexical variables in sign languages. In Effi Georgala \& Jonathan Howell (eds.), Proceedings from Semantics and Linguistic Theory 15, 152-168. Ithaca, NY: CLC Publications.

Quer, Josep. 2011. Reporting and quoting in signed discourse. In Elke Brendel, Jörg Meibauer \& Markus Steinbach (eds.), Understanding quotation, 277-302. Berlin: Mouton de Gruyter.

Quer, Josep. 2013a. Attitude ascriptions in sign languages and role shift. In Leah C. Geer (ed.), Proceedings of the $13^{\text {th }}$ Texas Linguistics Society Meeting, 12-28. Austin: Texas Linguistics Forum.

Quer, Josep. 2013b. A modality-free account of the position of clausal arguments. Manuscript, ICREA-Universitat Pompeu Fabra.

Quer, Josep \& Santiago Frigola. 2006. The workings of indexicals in role shift structures in Catalan Sign Language (LSC). Actes del 7è Congrés de Lingüística General, Universitat de Barcelona. CD-ROM.

Quer, Josep \& Joana Rosselló. 2013. On sloppy readings, ellipsis and pronouns: Missing arguments in Catalan Sign Language (LSC) and other argument-drop languages. In Victoria Camacho-Taboada, Ángel Jiménez-Fernández, Javier Martín-González \& Mariano Reyes-Tejedor (eds.), Information structure and agreement, 337-370. Amsterdam: John Benjamins. 
Quinto-Pozos, David. 2007. Can constructed action be considered obligatory? Lingua 117(7). 1285-1314.

Schlenker, Philippe. 2010. Role shift and context shift. Paper presented at Theoretical Issues in Sign Language Research (TISLR 10), Purdue University.

Vallduví, Enric. 1992. The informational component. PhD dissertation, University of Pennsylvania.

Wilbur, Ronnie B. \& Cynthia Patschke. 1999. Syntactic correlates of brow raise in ASL. Sign Language \& Linguistics 2(1). 3-41.

Zucchi, Alessandro. 2004. Monsters in the visual mode? Manuscript, Università degli Studi di Milano. 